\title{
Infantile hepatic hemangiomas associated with high-output cardiac failure and pulmonary hypertension
}

\author{
Xin-tong Zhang, Wei-dong Ren ${ }^{*} \mathbb{D}$, Guang Song, Yang-jie Xiao, Fei-fei Sun and Nan Wang
}

\begin{abstract}
Background: Infantile hepatic hemangioma $(\mathrm{IHH})$ is a rare endothelial cell neoplasm, which may be concurrent with severe complications and result in poor outcomes. Moreover, the coexistence of $\mathrm{HH}$ and congenial heart disease is even rarer.

Case presentation: We present a 10-day-old male born with $\mathrm{IHH}$ associated with patent ductus arteriosus (PDA), atrial septal defect (ASD) and pulmonary hypertension. Moreover, we reviewed a series of studies of $\mathrm{HH}$-associated high-output cardiac failure between 1974 and 2018, and summarized the treatment outcomes.

Conclusions: Infantile hepatic hemangioma $(\mathrm{IHH})$ has been known to induce high-output heart failure. There is no literature to summarize the severity of its impact on heart, which can lead to a high mortality rate. When $\mathrm{HH}$ is detected by ultrasound, the heart should be evaluated to facilitate treatment. The outcomes of $\mathrm{HH}$ associated with heart failure are good.
\end{abstract}

Keywords: Infantile hepatic hemangioma, Pulmonary hypertension, Congestive heart failure, Congenital heart disease

\section{Background}

Infantile hepatic hemangioma ( $\mathrm{IHH})$ is a rare proliferative endothelial cell tumor. It appears to be a benign tumor, however, it may lead to poor outcomes because of severe complications such as congestive heart failure (CHF), which occurs in 15\% of infants with this disease [1]. More rarely, IHH is concurrent with congenital heart disease (CHD). Herein we present a patient with $\mathrm{IHH}$, patent ductus arteriosus (PDA), and atrial septal defect (ASD). Meanwhile, we review and summarize the injury of IHH on the heart, and related outcomes.

\section{Case presentation}

A 10-day-old boy was born at 38 weeks' gestation and had tachypnea at 65 breaths per minute. The liver margin was palpable $4 \mathrm{~cm}$ below the left costal margin. The

\footnotetext{
* Correspondence: renwdcmu@163.com

Department of Ultrasound, Shengjing Hospital of China Medical University,

sanhao street 36\#, Shenyang 110004, CN, China
}

heart rhythm was normal but a grade II-IV systolic murmur could be heard. Laboratory tests showed that his brain natriuretic peptide (BNP) level was greater than $5000 \mathrm{pg} / \mathrm{ml}$. His CKMB was $110 \mathrm{U} / \mathrm{L}, \mathrm{C}$-reactive protein was $23.4 \mathrm{mg} / \mathrm{L}$, alpha fetoprotein was greater than 1210 ng/ml, PTA 54\%, INR 1.6, APTT $50 \mathrm{~s}$, FIB $1.5 \mathrm{~g} / \mathrm{l}$, Ddimer $1064 \mu \mathrm{g} / \mathrm{L}, \mathrm{HGB}, 123 \mathrm{~g} / \mathrm{L}, \mathrm{MCH} 36.4 \mathrm{pg}$, total bilirubin (BilT)196.7 umol/L, BilD $13.2 \mathrm{umol} / \mathrm{L}$, ALT 44 $\mathrm{U} / \mathrm{L}$, and AST $23 \mathrm{U} / \mathrm{L}$. Blood gas analysis revealed that the carbon dioxide pressure was raised to $53.4 \mathrm{mmHg}$ and the oxygen partial pressure was $62.5 \mathrm{mmHg}$.

Echocardiography demonstrated a small PDA of 1.5$1.8 \mathrm{~mm}$ with right to left shunting, a large ASD with left to right shunting, and severe right atrial and right ventricular enlargement. A severe systolic pressure gradient of $70 \mathrm{mmHg}$ suggested marked elevation of pulmonary artery pressure at the near systemic level. (Fig. 1) Color Doppler scanning of the liver displayed abundant blood flow in the lesion. (Fig. 2) The left hepatic vein was

(c) The Author(s). 2019 Open Access This article is distributed under the terms of the Creative Commons Attribution 4.0 International License (http://creativecommons.org/licenses/by/4.0/), which permits unrestricted use, distribution, and reproduction in any medium, provided you give appropriate credit to the original author(s) and the source, provide a link to the Creative Commons license, and indicate if changes were made. The Creative Commons Public Domain Dedication waiver (http://creativecommons.org/publicdomain/zero/1.0/) applies to the data made available in this article, unless otherwise stated. 


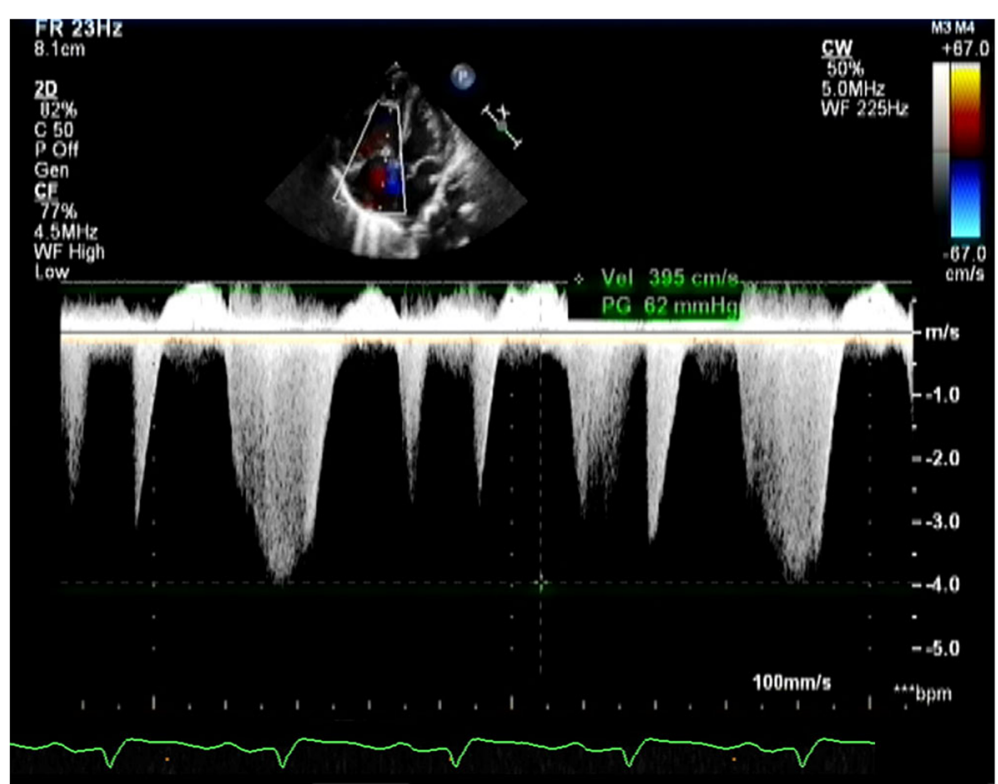

Fig. $1 \mathrm{HH}$ (Infantile hepatic hemangiomas) on abdominal ultrasound, in the left hepatic lobe. CDFI(Color doppler flow imaging) can be detected with abundant blood flow signals

dilated to $8 \mathrm{~mm}$ with two great branches feeding the mass. (Fig. 3)The right hepatic artery and a branch arising from the abdominal aorta were also in close association with the lesion.

Contrast-enhanced computed tomography (CT) showed that the lesion enhanced irregularly in the left lobe of the liver. (Fig. 4)It was irregularly hypodense on plain scan with peripheral enhancement in the arterial phase and centripetal fill-in in the portal venous phase. In the delayed phases, the density of the leision was slightly higher than that of the liver parenchyma. The patient received diuretic therapy, fluid restriction, lowflow oxygen, and infection control for the management of the heart failure. After treatment his breathing difficulty improved. Then the patient was transferred to Beijing Children's Hospital for surgery and the adhesion

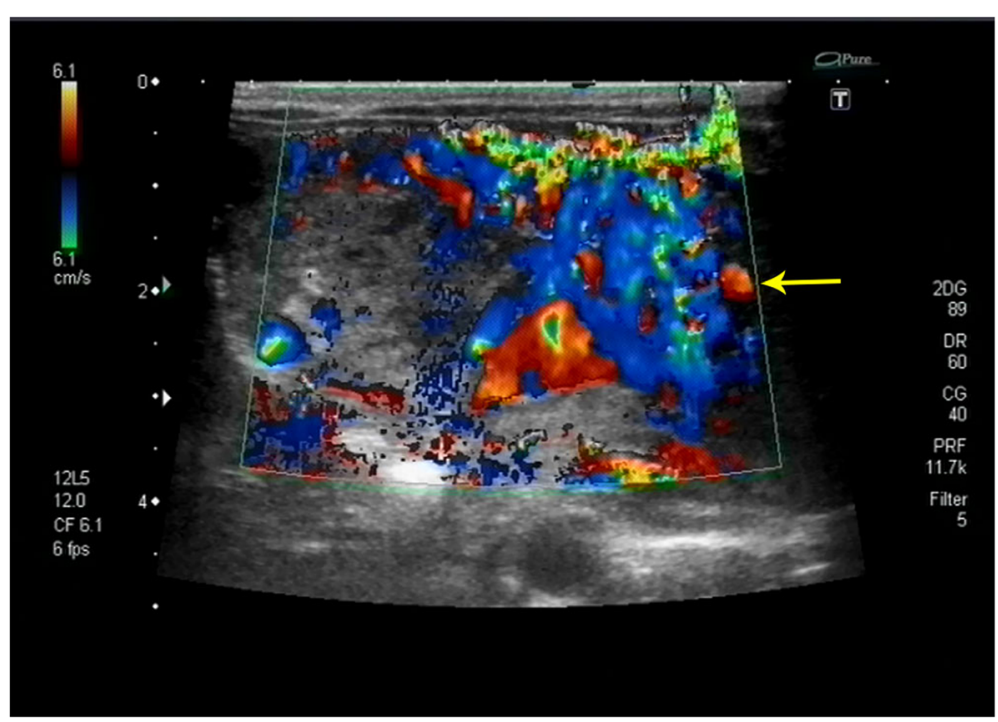

Fig. 2 Views of the IHH from contrast-enhanced CT (Contrast-enhanced computed tomography). The left hepatic lobe is irregularly enhanced with a slightly lower density and the lesion shows peripheral enhancement of centripetal fill-in on arterial phase 


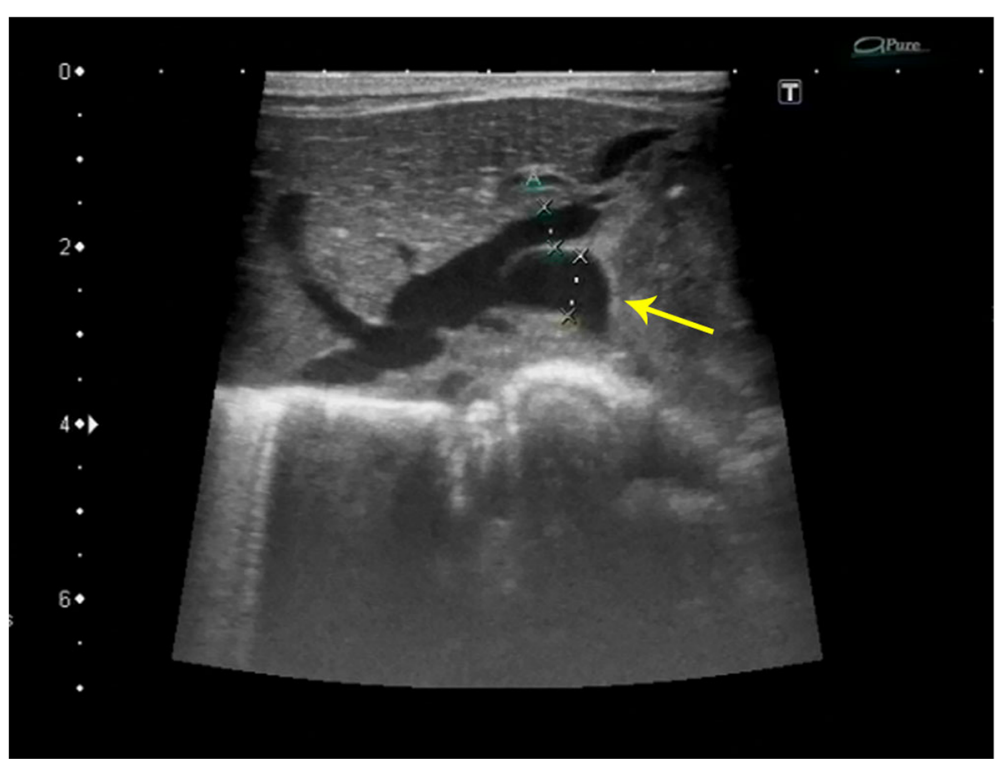

Fig. 3 Expansion of the left hepatic vein close to the lesion

between the tumor and the intestine was found during the operation. The patient eventually died due to postoperative complications and multiple organ failure.

\section{Discussion and conclusions}

$\mathrm{IHH}$ is an endothelial cell neoplasm, a benign tumor, which is usually clinically silent and slowly progressive during childhood. Although almost all are asymptomatic, a small subset can produce high-output cardiac failure and cause considerable mortality. Its pathologic changes are similar to that of hepatic artery to hepatic vein or hepatic artery to portal vein arteriovenous fistula. The prognosis of the disease is poor when complications present and the mortality rate can be as high as $90 \%[2,3]$. We reviewed a series of recent studies of $\mathrm{IHH}$-associated high-output cardiac failure between 1974 and 2018, and summarized the treatment outcomes.
Heart failure was obviously a clinical relevant complication in the 25 cases which were presented in Table 1 $[2,4-22]$. The age of diagnosis varied ranging from 1 day to 3.5 years. Eight patients (28\%) presented with pulmonary hypertension including two mild, one moderate, three severe, and two unknown. Two of them were also associated with other congenital cardiac malformations which were illustrated in detail in Table 2 [7, 11, 13, 22-24]. Cardiac function improved after treatment in 15 patients, achieving normal value in 2 . Consequently the outcomes of $\mathrm{IHH}$-associated high-output cardiac failure proved to be quite satisfying. Most of the patients discharged or achieved remarkable improvement through appropriate treatment, while only 4 of them failed to survive.

IHH can be classified as focal, multifocal, or diffuse [9]. The diagnosis of $\mathrm{IHH}$ relies on ultrasonography

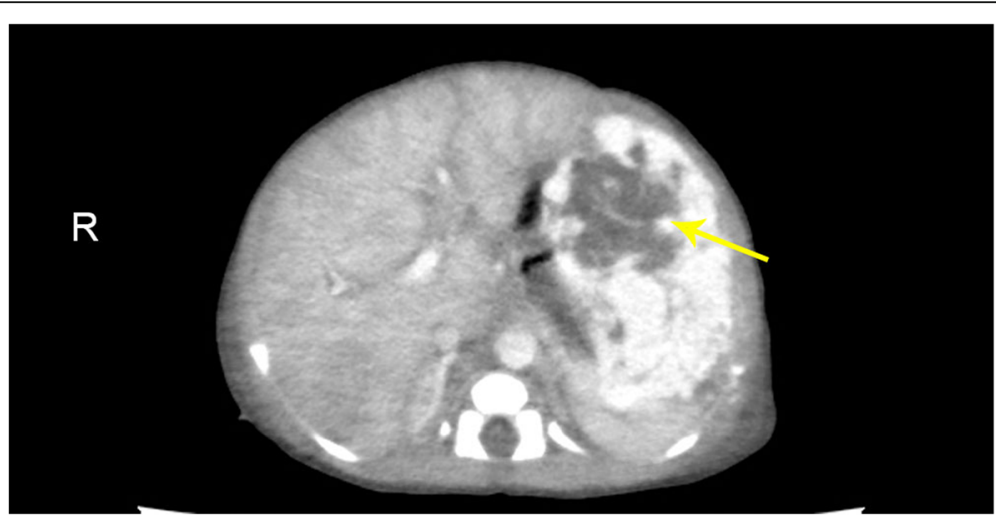

Fig. 4 View of the patient's moderate to severe pulmonary arterial pressure 
Table 1 Summary of the literature on patients presenting with $\Perp \mathrm{HH}$ associated with congestive heart failure

\begin{tabular}{|c|c|c|c|c|c|c|c|}
\hline Study & Age & Sex & Cardiopathy & $\begin{array}{l}\text { Diagnose } \\
\text { methods }\end{array}$ & Treatment & Cardiac recovery & Outcome \\
\hline Mattioli et al. (1974) [16] & $27 d$ & $\mathrm{~F}$ & $\mathrm{BVH}, \mathrm{PAH}$ & HAG & Ligation & Normal & Discharged \\
\hline Linderkamp et al. (1976) [14] & $1 d$ & M & $\mathrm{CHF}$ & Renal scan & Resection & Improve & Discharged \\
\hline Rotman et al. (1980) [18] & $4 \mathrm{~m}$ & $\mathrm{~F}$ & $\mathrm{CHF}$ & VG & Glucocorticoid & Improve & $\begin{array}{l}\text { Remarkable } \\
\text { improvement }\end{array}$ \\
\hline Burke et al. (1986) [2] & $3.5 y$ & $\mathrm{~F}$ & Cardiomegaly & US,CT & Embolization & - & Failure \\
\hline Gozal et al. (1990) [9] & $17 d$ & $\mathrm{~F}$ & Cardiomegaly & US & Glucocorticoid & Improve & Discharged \\
\hline \multirow[t]{3}{*}{ Kristidis et al. (1991) [13] } & $3 d$ & M & $\mathrm{ASD}, \mathrm{BV} H, \mathrm{PDA}$ & US & Prednisone & Improve & Discharged \\
\hline & $3 d$ & M & $\mathrm{CHF}$ & US & Prednisone,digoxin & Improve & Discharged \\
\hline & $1 d$ & $\mathrm{~F}$ & $\mathrm{CHF}$ & US & Prednisone & Improve & Discharged \\
\hline Barsever et al. (1994) [4] & $2 w$ & $\mathrm{~F}$ & CHF cardiomegaly & US,CT & Interferon & - & $\begin{array}{l}\text { Remarkable } \\
\text { improvement }\end{array}$ \\
\hline Hazebroek et al. (1995) [10] & $2 d$ & M & $\mathrm{CHF}$ & US,HAG & Ligation & Improve & $\begin{array}{l}\text { Remarkable } \\
\text { improvement }\end{array}$ \\
\hline Fok et al. (1996) [8] & $1 d$ & M & $\mathrm{CR}=0.77, \mathrm{CHF}$ & US,TRA & Embolization & - & Discharged \\
\hline \multirow[t]{2}{*}{ Lu C C et al. (2002) [15] } & $1 d$ & $\mathrm{~F}$ & $C R=0.8$ & US,CT & Glucocorticoid,dopamine & 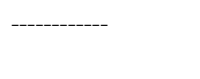 & $\begin{array}{l}\text { Remarkable } \\
\text { improvement }\end{array}$ \\
\hline & $10 d$ & M & $\mathrm{BVH}$ & US,MRI & Ligation & Improve & Discharged \\
\hline Sakamoto et al. (2010) [19] & $4 d$ & $\mathrm{~F}$ & $\mathrm{CHF}$ & $C T$ & Transplantation & - & $\begin{array}{l}\text { Remarkable } \\
\text { improvement }\end{array}$ \\
\hline \multirow[t]{2}{*}{ Mhanna et al. (2011) [17] } & $8 w$ & $\mathrm{~F}$ & $\mathrm{CHF}$ & US,CT & Glucocorticoid,propranolol & --1-1--- & Discharged \\
\hline & $3 \mathrm{~m}$ & M & ASD,CHF,LVH,PDA & US & Glucocorticoid,propranolol & ----o--- & Discharged \\
\hline Dotan et al. (2013) [7] & $11 \mathrm{w}$ & $\mathrm{F}$ & $\mathrm{BVH}, \mathrm{PAH}$ & US & propranolol & Improve & Discharged \\
\hline Dasgupta et al. (2013) [6] & $1 d$ & M & $\mathrm{BVH}$ & US,CT & Glucocorticoid & Improve & $\begin{array}{l}\text { Remarkable } \\
\text { improvement }\end{array}$ \\
\hline Chopra et al. (2014) [5] & $9 \mathrm{~m}$ & $\mathrm{~F}$ & $\mathrm{CHF}$ & US,CT & Glucocorticoid & - & Failure \\
\hline Ye et al. (2014) [14] & $59 d$ & $\mathrm{~F}$ & $\mathrm{PAH}, \mathrm{RVH}$ & US,MRI & Surgery & - & Failure \\
\hline Imai et al. (2015) [12] & $1 d$ & M & Cardiomegaly & $\mathrm{MRI}, \mathrm{CT}$ & Glucocorticoid & Improve & Discharged \\
\hline \multirow[t]{2}{*}{ Wang et al. (2015) [24] } & $5 \mathrm{~m}$ & $\mathrm{~F}$ & Cardiomegaly,PA & US,CT & Embolization & Improve & $\begin{array}{l}\text { Discharged } \\
\text { Failure }\end{array}$ \\
\hline & $19 d$ & $\mathrm{~F}$ & $\mathrm{H}$ BVH,PAH & US,CT & Embolization & Improve & \\
\hline Shen et al. (2016) [20] & $11 d$ & M & $\mathrm{CHF}$ & US & Glucocorticoid, Embolization & Normal & Discharged \\
\hline Hutchins et al. (2017) [11] & $22 \mathrm{~m}$ & $\mathrm{~F}$ & VSD & US,CT,MRI & Glucocorticoid,Sirolimus & - & Discharged \\
\hline
\end{tabular}

BVH Biventricular hypertrophy, RVH Right ventricular hypertrophy, "-_" No information available, CR Cardiothoracic ratio, VG Venacavography, HAG Hepatic arterograph

(US), CT, and magnetic resonance imaging (MRI). CT and MRI can reveal discrete lesions in patients. Diffuse lesions require baseline determination of size, cardiac and thyroid function, and coagulation profile. When $\mathrm{IHH}$ is associated with heart disease, cardiac structure and function can be observed by echocardiography, which can identify intra- or extracardiac disease [3]. There were $13(52 \%)$ patients in our series that were diagnosed by echocardiography. In our case, the patient had a focal lesion, which is diagnosed primarily by ultrasonography and CT.

The pathological mechanism of CHF in $\mathrm{IHH}$ is associated with arteriovenous shunts in hemangiomas.
The arteriovenous shunts result in a decrease of systemic blood volume as well as increase of pulmonary blood volume, thus leading to the cardiac output increase. Furthermore, aggravated by the pulmonary hypertention it finally leads to high-output CHF [21]. In fetal stage, high pulmonary vascular resistance and pulmonary pressure help maintain the fetal circulation, however, after birth the high pulmonary pressure will descend gradually within 3 months while systemic pressure of neonates will ascend with closure of oral foramen. Nevertheless, the existence of $\mathrm{IHH}$ can increase the load of right heart system and affect circulation transition from fetus to neonate, which 
Table 2 Summary of patients presenting with $\mathrm{IHH}$ associated with pulmonary artery hypertension

\begin{tabular}{|c|c|c|c|c|c|c|c|c|}
\hline Study & Sex & Age & $\mathrm{EF}(\%)$ & Heart & TR & PAH mmHG & PDA & VSD,ASD \\
\hline Present study & $M$ & $10 d$ & 72 & RHE & moderate & 70 & $\begin{array}{l}1.5-1.8 \mathrm{~mm} \\
\text { R-L }\end{array}$ & ASD $7.5 \mathrm{~mm} \mathrm{L-R}$ \\
\hline Wang et al. (2015) [24] & $\mathrm{F}$ & $5 \mathrm{~m}$ & 78 & cardiomegaly & - & 54 & - & - \\
\hline \multirow[t]{2}{*}{ Kristidis et al. (1991) [13] } & $\mathrm{F}$ & $19 d 3 d$ & 64 & RHE cardiomegaly & severe & $90 \mathrm{PAH}$ & -- & -- \\
\hline & $\mathrm{F}$ & & -- & & -- & & -- & Small ASD L-R \\
\hline Dotan et al. (2013) [7] & $\mathrm{F}$ & $11 w$ & normal & $\mathrm{BVH}$ & mild to moderate & 58 & - & - \\
\hline Ye et al. (2014) [22] & $\mathrm{F}$ & $59 d$ & - & RHE & - & 120 & - & - \\
\hline Ersch et al. (2002) [23] & $\mathrm{F}$ & $20 m$ & - & RHE & - & $\mathrm{PAH}$ & - & - \\
\hline Hutchins et al. (2017) [11] & $\mathrm{F}$ & $22 \mathrm{~m}$ & - & RHE & mild to moderate & 70 & - & Small VSD \\
\hline
\end{tabular}

RHE Right heart enlargement, $B V H$ Biventricular hypertrophy, $P D A$ Patent ductus arteriosus, $R-L$ Right to left shunt, $L-R$ Left to right shunt, $T R$ Tricuspid regurgitation, -- No information available

further increase pulmonary vascular resistance and cause pulmonary hypertention.

Various therapies have been reported to treat $\mathrm{IHH}$, including drugs, embolization, ligation, and resection [25]. (1) Drugs: steroid therapy functioned well in improving hemodynamics, reducing hepatic vascularity as well as deferring early emergency delivery in congestive heart failure fetus as recorded in literatures. There are no significant differences between single or combined drug use in the literature. (2) Embolization: embolization has been strongly suggested for provisional stabilization of fatal congestive heart failure combined with pharmacological therapy. (3) Ligation: ligation can reduce oxygen supply to hepatocytes and improve liver function. (4) Resection: surgery should be considered when medical management failed [3].Treatment methods and their outcomes as described in the literature are

Table 3 Demographics for treatment outcomes

\begin{tabular}{llll}
\hline $\mathrm{HH}$ & All & Success & Failure \\
\hline Embolization & 5 & 3 & 2 \\
Ligation & 3 & 3 & 0 \\
Resection & 1 & 1 & 0 \\
Transplantation & 1 & 1 & 1 \\
Drugs: & 10 & 9 & 1 \\
Glucocorticoid propranolol & 2 & 2 & 0 \\
Glucocorticoid dopamine & 1 & 1 & 0 \\
Prednisone digoxin & 1 & 1 & 0 \\
Glucocorticoid & 5 & 4 & 1 \\
Propranolol & 1 & 1 & 0 \\
Prednisone & 2 & 2 & 0 \\
Interferon & 1 & 1 & 0 \\
Glucocorticoid,Sirolimus & 1 & 1 & 0 \\
& 25 & 21 & 4 \\
\hline
\end{tabular}

Success $=$ remarkable improvement or discharged shown in Table 3. Among 25 patients, four ended in treatment failure (18\%).

Early age of onset is typical of IHH with heart failure. When IHH is detected by US, echocardiography should also be performed timely for more detailed information about cardiac structure and function. For infants in lifethreatening and complicated conditions, US and echocardiography should be performed as early as possible to evaluate $\mathrm{IHH}$ associated with congestive heart failure and to facilitate treatment therapies. With regard to the treatment in our review, outcomes of IHH with heart failure are considered to be good.

\section{Abbreviations}

ALT: Alanine aminotransferase; APTT: Activated partial thromboplastin time; ASD: Atrial septal defect; AST: Aspartate aminotransferase; BilD: Direct bilirubin; BilT: Total bilirubin; BNP: Brain natriuretic peptide; CHF: Congestive heart failure; CKMB: MB isoenzyme of creatine kinase; PTA: Prothrombin time activity; CT: Computed tomography; FIB: Fibrinogen; HGB: Hemoglobin; IHH: Infantile hepatic hemangioma; INR: International normalized ratio; MCH: Mean corpuscular hemoglobin; MRI: Magnetic resonance imaging; PDA: Patent ductus arteriosus; US: Ultrasonography

\section{Acknowledgements}

We thank Dr. Ying Ren for the computed tomography image acquisition.

\section{Authors' contributions}

F-FS and NW performed echocardiographic examination and collected the images. Y-JX and GS participated in the design of the study and performed data analysis. W-DR revised critically for important intellectual content before manuscript submitted. X-TZ drafted the manuscript. All authors read and approved the final manuscript.

\section{Funding}

This study was supported by grants from National natural Science Foundation of China (81571686 to W.D.R) and National natural Science Foundation of Liaoning (2018053064 to F.F.S). The funding bodies assisted in the collection of clinical datas and publication fees.

\section{Availability of data and materials}

All data that was generated or analyzed during the current study are available from the corresponding author on reasonable request.

\section{Ethics approval and consent to participate}

The study has been approved by the ethics committee of Shengjing Hospital of China Medical University, Shenyang, China. 


\section{Consent for publication}

Written informed consent was obtained from the parents of the patient for publication of this case report and any identifying images.

\section{Competing interests}

The authors declare that they have no competing interests.

Received: 24 February 2019 Accepted: 23 September 2019

Published online: 11 October 2019

\section{References}

1. Selby DM, Stocker JT, Waclawiw MA, Hitchcock CL, Ishak KG. Infantile hemangioendothelioma of the liver. Hepatology. 2010;20(1):39-45.

2. Burke DR, Verstandig A, Edwards O, Meranze SG, McLean GK, Stein EJ. Infantile hemangioendothelioma: angiographic features and factors determining efficacy of hepatic artery embolization. Cardiovasc Intervent Radiol. 1986;9(3):154-7.

3. Samuel M, Spitz L. Infantile hepatic hemangioendothelioma: the role of surgery. J Pediatr Surg. 1995;30(10):1425-9.

4. Bar-Sever Z, Horev G, Lubin E, Kornreich L, Naor N, Ziv N, Shimoni A Grunebaum M. A rare coexistence of a multicentric hepatic hemangioendothelioma with a large brain hemangioma in a preterm infant. Pediatr Radiol. 1994;24(2):141-2.

5. Chopra R, Arora P, Yadav RK. Diagnosis of infantile hemangioendothelioma of the liver by triple phase computed tomography. Int J Contemp Pediatrics. 2014;1(3):184-6.

6. Dasgupta MK, Das S, Patra C, Sarkar S. Symptomatic infantile hepatic hemangioendothelioma successfully treated with steroid. J Clin Neonatol. 2013;2(4):187-9

7. Dotan $\mathrm{M}$, Lorber $\mathrm{A}$. Congestive heart failure with diffuse neonatal hemangiomatosis--case report and literature review. Acta Paediatr. 2013; 102(5):e232.

8. Fok TF, Chan MS, Metreweli C, Ng PC, Yeung CK, Li AK. Hepatic haemangioendothelioma presenting with early heart failure in a newborn: treatment with hepatic artery embolization and interferon. Acta Paediatr. 1996;85(11):1373-5.

9. Gozal D, Saad N, Bader D, Berger A, Jaffe M. Diffuse neonatal haemangiomatosis: successful management with high dose corticosteroids. Eur J Pediatr. 1990;149(5):321-4.

10. Hazebroek FW, Tibboel D, Robben SG, Bergmeyer JH, Molenaar JC. Hepatic artery ligation for hepatic vascular tumors with arteriovenous and arterioportal venous shunts in the newborn: successful management of two cases and review of the literature. J Pediatr Surg. 1995;30(8):1127-30.

11. Hutchins KK, Ross RD, Kobayashi D, Martin A, Rajpurkar M. Treatment of refractory infantile hemangiomas and pulmonary hypertension with Sirolimus in a pediatric patient. J Pediatr Hematol Oncol. 2017;39(7):e391-3.

12. Imai H, Hidaka N, Murakami T, Kido S, Yumoto Y, Fukushima K, Kato K. In utero sonographic findings of Giant hepatic hemangioma and associated perinatal complications: a report of two cases. J Med Ultrasound. 2015;23(1):46-51.

13. Kristidis P, de Silva M, Howman-Giles R, Gaskin KJ. Infantile hepatic haemangioma: investigation and treatment. J Paediatr Child Health. 1991; 27(1):57-61.

14. Linderkamp O, Hopner F, Klose H, Riegel K, Hecker WC. Solitary hepatic hemangioma in a newborn infant complicated by cardiac failure, consumption coagulopathy, microangiopathic hemolytic anemia, and obstructive jaundice. Case report and review of the literature. Eur J Pediatr. 1976;124(1):23-9.

15. Lu CC, Ko SF, Liang CD, Kuo HW, Tiao MM. Infantile hepatic hemangioendothelioma presenting as early heart failure: report of two cases. Chang Gung Med J. 2002;25(6):405-10.

16. Mattioli $L$, Lee $K R$, Holder TM. Hepatic artery ligation for cardiac failure due to hepatic hemangioma in the newborn. J Pediatr Surg. 1974:9(6):859-62.

17. Mhanna A, Franklin WH, Mancini AJ. Hepatic infantile hemangiomas treated with oral propranolol--a case series. Pediatr Dermatol. 2011;28(1):39-45.

18. Rotman M, John M, Stowe S, Inamdar S. Radiation treatment of pediatric hepatic hemangiomatosis and coexisting cardiac failure. N Engl J Med. 1980;302(15):852.

19. Sakamoto S, Kasahara M, Shigeta T, Fukuda A, Kakiuchi T, Miyasaka M, Nosaka S, Nakano N, Nakagawa A, Horikawa R. Living donor liver transplantation for multiple intrahepatic portosystemic shunts after involution of infantile hepatic hemangiomas. J Pediatr Surg. 2011;46(6): 1288-91.

20. Shen WC, Liang PC, Wu JF, Hsu CT, Chen HS, Chen HL. Combined Transarterial embolization and propranolol as effective treatment for hepatic hemangioma with Kasabach-Merritt syndrome and heart failure in a neonate. Pediatr Neonatol. 2017:58(2):191-3.

21. Wang T, Wang Y, Liang Y, Lu G. Infantile hepatic Hemangioendothelioma associated W'ith congestive heart failure: two case reports with different outcomes. Medicine (Baltimore). 2015;94(52):e2344.

22. Ye JJ, Shao YC, Shu Q. Imaging findings of multiple infantile hepatic hemangioma associated with cardiac insufficiency. World J Pediatr. 2014; 10(4):368-70.

23. Ersch J, Banziger $\mathrm{O}$, Braegger $\mathrm{C}$, Arbenz U, Stallmach T. An infant with pulmonary hypertension due to a congenital Porto-caval shunt. Eur J Pediatr. 2002;161(12):660-2.

24. Wang T, Wang Y, Liang Y, Lu G. Infantile hepatic Hemangioendothelioma associated with congestive heart failure: two case reports with different outcomes. Medicine (Baltimore). 2015;94(52):e2344.

25. Ozyer U, Kirbas I, Aytekin C, Hasdogan B. Coil embolization of a congenital intrahepatic arterioportal fistula: increasing experience in management. Pediatr Radiol. 2008;38(11):1253-6.

\section{Publisher's Note}

Springer Nature remains neutral with regard to jurisdictional claims in published maps and institutional affiliations.

\section{Submit your next manuscript to BioMed Central} and we will help you at every step:

- We accept pre-submission inquiries

- Our selector tool helps you to find the most relevant journal

- We provide round the clock customer support

- Convenient online submission

- Thorough peer review

- Inclusion in PubMed and all major indexing services

- Maximum visibility for your research

Submit your manuscript at www.biomedcentral.com/submit
C) Biomed Central 